\title{
DENGUE HAEMORRHAGIC FEVER WITH BRADYCARDIA
}

\author{
$\mathrm{SM} \mathrm{ARIF}^{1}{ }^{1} \mathrm{H}_{\mathrm{AHMED}}{ }^{2}, \mathrm{KZ} \mathrm{KHOKON}^{3}, \mathrm{AK} \mathrm{AZAD}^{4}, \mathrm{MA} \mathrm{FAIZ}^{5}$
}

\section{Introduction:}

Dengue fever (DF) and dengue hemorrhagic fever (DHF) is a viral disease, caused by dengue (DEN) virus and transmitted by bites of Aedes aegypti mosquito. There are four serotypes of dengue viruses- DEN-1, DEN-2, DEN-3 and DEN-4.In Bangladesh dengue has started as epidemic \& has created panic among the people since the year $2000^{1}$ and as per the sero-survey findings, 3 sero-types of the virus circulating. ${ }^{2}$ Here we describe a case of DHF with subsequent cardiac complication, treated in Dhaka Medial College Hospital (DMCH).

\section{Case Report:}

Dr. X of 36 years, a known case of steroid dependent ulcerative colitis for 7 years, got admitted at DMCH on $30^{\text {th }}$ September 2007, with the complaints of remittent fever associated with chills, bodyache, malaise, severe headache for four days. He also had haematuria and black tarry stool since that morning. He had no history of rigor, convulsion, cough or burning micturation. The highest recorded temperature was $104^{0} \mathrm{~F}$ and the fever was poorly responsive to oral paracetamol. He had no history of traveling in a malaria endemic zone within the last 3 months.

On admission he had fever of $102^{\circ} \mathrm{F}$, mild dehydration, generalized macular rash with few ecchymoses over lower legs. There was no anemia, jaundice, oedema or lymphadenopathy. Systemic examination revealed no abnormality. A full blood count revealed; white blood cell count $6000 / \mathrm{mm}^{3}$ (with $64 \%$ neutrophils, $32 \%$ lymphocytes, and $4 \%$ monocytes), hemoglobin $13.6 \mathrm{~g} /$ dl; hematocrit $39 \%$; platelets $30,000 / \mathrm{mm} 3$. Serum sodium was $142 \mathrm{mmol} / \mathrm{l}$, potassium $3.23 \mathrm{mmol} / \mathrm{l}$, chloride $101 \mathrm{mmol} / \mathrm{l}$. His urinalysis showed $15-20 \mathrm{red}$ cells per HPF. Dengue IgM antibody by ELISA showed raised titer. He was diagnosed as a case of Dengue Haemorrhagic Fever Grade-II with steroid dependent ulcerative colitis. He was managed with intravenous fluid and whole blood according to national guideline. From $4^{\text {th }}$ day onward he became afebrile and there was no black tarry stool or red urine. But his pulse rate was found 52/minute. Electrocardiography (ECG) revealed junctional rhythm. He was treated with injection Atropine $0.5 \mathrm{mg}$ IV stat and his heart rate was increased to $76 /$ minute. A two dimensional echocardiogram showed left ventricular systolic dysfunction (ejection fraction 50\%). During the next two days, he was haemodynamically stable and was under intensive cardiac monitoring. On the $6^{\text {th }}$ day he gained sinus rhythm his platelet count raised to $180,000 / \mathrm{cmm}$. On day $7, \mathrm{Hb}$ was $13.3 \mathrm{gm} / \mathrm{dl}$ and platelet count was $200,000 / \mathrm{cmm}$ On the $9^{\text {th }}$ day he was discharged without any sequel.

\section{Discussion:}

Viral myocarditis is a well-recognised complication of many viruses leading to subsequent cardiomyopathies (dilated type). ${ }^{3}$ There are limited data available with respect to dengue virus involvement. ${ }^{4,5}$ In our unit in $\mathrm{DMCH}$ around 100 cases of dengue were treated in 2004. A number of articles in the last five years also described dengue. ${ }^{6}$ In the present report, the patient developed bradycardia on the $4^{\text {th }}$ day of hospital admission. Though there is no published data in Bangladesh on myocardial involvement in acute dengue infection but the present report is not the first one to suggest an association between dengue and cardiac involvement. Myocardial involvement may be a result of the direct effect of the dengue virus in susceptible individuals, or due to the effects of cytokine mediators and/or cellular components of the immune response. ${ }^{3}$ The possibility of IgM antibodies produced against the dengue virus cross-reacting with a myocardial antigen is unlikely, as ECG change was recovered two days later, when antibodies were still in circulation. Dengue haemmorrhagic fever patients

1. Associate Professor, Department of Medicine, Dhaka, Medical College

2. Medical Officer, Medicine Unit Green, Dhaka Medical College Hospital

3. Assistant Registrar, Medicine Unit Green, Dhaka Medical College Hospital

4. Medical Officer, Medicine Unit Green, Dhaka Medical College Hospital

5. Professor, Department of Medicine, Dhaka Medical College

Correspondence : Dr. SM Arif, Associate Professor, Department of Medicine, Dhaka, Medical College 
have higher levels of TNF-á, interleukins-6, -13 and 18, and cytotoxic factor. These cytokines are implicated in causing increased vascular permeability and shock during dengue infection ${ }^{7-9}$ but their contribution towards development of myocarditis remain undefined. ${ }^{3}$

Dengue virus can infect both CD-4 and CD-8 T cells. ${ }^{10}$ Following primary infection both serotype-specific and serotype-cross-reactive memory T cells are formed and which later, on secondary exposure to the virus, augment infection by producing various cytokines. ${ }^{11}$ These mechanisms may have a role in the pathogenesis of dengue associated myocarditis, although the exact pathophysiology is undefined.

In a study in SriLanka, transient chamber dilatation with a good ejection fraction and jerky wall motion were the major abnormalities, involving dominantly the right ventricle. ${ }^{3}$ Its thinner musculature may make the right ventricle more susceptible to dilatation. Relative bradycardia is a well described association with dengue fever ${ }^{12}$ but heart rate is not useful in predicting myocarditis. In an Indian study in 17 patients with cardiac involvement in dengue haemorrhagic fever/dengue shock syndrome (DHF/ DSS), showed global hypokinesia in 70.6\%. ${ }^{13} 99 \mathrm{Tc}$ pyrophosphate imaging carried out in four patients showed no myocardial necrosis. In the Indian study, only 5/17 (29\%) had ECG changes in presence of dengue haemorrhagic fever/DSS. These five patients showed ST and T wave changes with ECG changes, echocardiographic and radionuclide ventriculography all returning to normal within three weeks, as in SriLankan study, contradicting predictions made by Obeysekara et al. ${ }^{14,15}$ In another Indian study, in children with dengue haemorrhagic fever, there was no correlation between myocardial involvement and clinical severity. ${ }^{16}$ Why certain individuals had a predilection for myocardial involvement is unknown. Virulence factors and geographic variation seem unlikely.

\section{Conclusions:}

Myocardial involvement of dengue infections run a benign course without long-term complications, contrary to what was believed in the past. Dengue myocarditis is exclusively asymptomatic with no long term sequele. Two-dimensional echocardiography is the only reliable tool of investigation.

\section{References:}

1. Bakar A, Ahsan HAMN, Ahsan M, Mamun AA, Karim SR. Emergence of Dengue in Bangladesh. PAFMJ 2004;54(2):147-50.
2. World Health Organization - Bangladesh 2009. (accessed on 9th January, 2009) URL:[http:// www.whoban.org/communicable_dis_dengue.html]

3. Satarasinghe R L, Arultnithy K, Amerasena NL et al. Asymptomatic myocardial involvement in acute dengue virus infection in a cohort of adult Sri Lankans admitted to a tertiary referral centre. Br J Cardiol 2007;14:171-3

4 Buan WH, Ton G. Cardiac involvement in haemorrhagic fever. J Singapore Paed Soc 1967;9:28.

5. Hyman AS. The heart in dengue. Some observations made among Navy and Marine combat units in South Pacific. War Medicine (Chicago) 1943; 4:497.

6. Banu LA, Hossain SMM. Study of dengue fever, dengue hemorrhagic fever, dengue shock syndrome, 100 cases admitted in DMCH. J Dhaka Med Coll; 2002; $11: 3$.

7. Mustafa AS, Elbishbishi EA, Agarwal R et al. Elevated levels of interleukin-13 and IL- 18 in patients with dengue hemorrhagic fever. Immunol Med Microbiol 2001; 30:229- 33.

8. Vitarana T, de Silva H, Withana $\mathrm{N}$ et al. Elevated tumour necrosis factor in dengue fever and dengue haemorrhagic fever. Ceylon Med J 1991; 36:63-5.

9. King CA, Marshall JS, Alshurafa $\mathrm{H}$ et al. Release of vasoactive cytokines by antibody-enhanced dengue virus infection of a human mast cell/basophil line. $\mathrm{J}$ Virol 2000; 74:7146-50.

10. Mentor NA, Kurane I. Dengue virus infection of human T lymphocytes. Acta Virol 1997; 41:175-6.

11. Kurane I, Innis BL, Nimmannitya S et al. Human immune responses to dengue viruses. Southeast Asian J Trop Med Public Health 1990; 21:658- 62.

12. Nimmannitiya S. Dengue and dengue hemorrhagic fever. In: Manson's Tropical Diseases 20th ed, London: WB Saunders, 1996; 712-29.

13. Wali JP, Biswas A, Chandra S et al. Cardiac involvement in dengue haemorrhagic fever. Int $\mathrm{J}$ Cardiol 1998; 64:31-6.

14. Obeysekara I, Yvette H. Myocarditis and cardiomyopathy after arbo virus infection, (dengue and chickengunya fever). Br Heart J 1972; 34: 821-7

15. Obeysekara I, Yvette H. Arbovirus heart disease. Myocarditis and cardiomyopathy following gangue fever and chickengunya fever. A follow up study. Am Heart J 1973;85:186-94.

16. Kabra JK, Juneya R, Madhulika J et al. Myocardial dysfunction in children with dengue haemorrhagic fever. Natl Med J India 1998; 11(2):59-61. 